\title{
Effect of Hydrophobic Surface Treatment in Lowering Ionic Transport into Concrete
}

\author{
Ki Hwan Kim, ${ }^{1}$ Min Jae Kim, ${ }^{2}$ Hansol Kim, ${ }^{1}$ and Ki-Yong Ann ${ }^{1}{ }^{1}$ \\ ${ }^{1}$ Department of Civil and Environmental Engineering, Hanyang University, Ansan 15588, Republic of Korea \\ ${ }^{2}$ Department of Civil, Environmental, and Architectural Engineering, Korea University, Seoul 02841, Republic of Korea
}

Correspondence should be addressed to Ki-Yong Ann; kann@hanyang.ac.kr

Received 26 March 2020; Accepted 29 April 2020; Published 20 May 2020

Academic Editor: Yuqing Zhang

Copyright ( $\odot 2020 \mathrm{Ki}$ Hwan Kim et al. This is an open access article distributed under the Creative Commons Attribution License, which permits unrestricted use, distribution, and reproduction in any medium, provided the original work is properly cited.

The present study concerns hydrophobic surface treatments with silane-based liquid and crème on the concrete surface against external ionic transport for the application to concrete pavement coating. To quantify their effectiveness in mitigating the ionic penetration, water absorption and chloride transport were measured. Especially, back-scattered image analysis and the electrochemical impedance spectroscopy were used to identify the effect of pore-blocking at the interface of coating agents and the concrete. As a result, the surface treatment with both liquid and crème could significantly reduce the water absorption and chloride ingresses at all depths of measured concrete, due to a modification of the porosity. Moreover, the surface treatment on concrete substrate increased the polarization resistance, thereby enhancing the resistance to ionic transport into the concrete, and the crème type was slightly more effective at the same dosage of treatment.

\section{Introduction}

To mitigate the risk of steel corrosion in concrete on roadway structure, there have been a number of preventive measures such as a modification of concrete mix design, application of corrosion inhibitor, electrochemical treatment, and barrier coating on the steel surface. These means have been successfully adopted in preventing the onset of steel corrosion in concrete, arising from the reinforced passivity of the steel or/and lowering the transport rate of corrosive ions. However, adverse issues may be always accompanied in terms of a reduction of structural properties. For example, calcium nitrite-based corrosion inhibitor is evidently effective in enhancing the corrosion resistance, but a development of the concrete strength was inversely lowered in long-term use [1]. Moreover, the rate of chloride transport in concrete containing nitrite ions was much accelerated than unused one [2], and thus the benefit of the chemical inhibitor would be offset in prolonging the corrosion-free life. When it comes to electrochemical treatment (i.e., cathodic protection), the corrosive agents could be effectively arrested and then mostly nullify the corrosion behavior. However, in the process of electrochemical treatment, a debonding of steel from the concrete body often occurs; in fact, the bond strength between steel and concrete is reduced by $30-60 \%$ under electric charge [3]. Barrier coating also accompanies the potential risk of debonding between steel and concrete, arising from increased porosity at the interfacial zone, leading to independent structural behavior of the concrete structures $[4,5]$. Thus, it has been required to develop a preventive mean against corrosive ions and molecules with no influence on the fundamental properties of concrete.

The surface treatment may be an alternative to mitigate corrosion risk with no adverse effect because it marginally affects the fundamental properties of concrete such as strength or fresh setting. The surface treatment agents have been developed representatively in three different purposes of treatment effect: pore-blocking, surface coating, and porelining [6-8]. As for pore-blocking, insoluble phases are formed inside concrete pores which are formed at the nearer surface of the cover concrete, by a chemical reaction between agents and solvent. However, to be effective in blocking the pore network, the agents must be fully percolated into the 
concrete cover, being always limited by the condition of concrete such as humidity and dust on the surface. In case of surface coatings, polymeric materials are usually painted on the surface of the concrete so that all aggressive ions could be prevented from penetrating into concrete. Thus, it is expected that no corrosive ions and molecules could be present in concrete. However, the surface coating is often detached from the concrete surface within a decade of years by the limited bond between the two different materials. To maintain the inhibitive nature of concrete against external ions, the surface coating must be regularly reapplied at a certain interval. Substantially, pore-lining seems more realistic in that agents could be more easily penetrated into inner concrete to coat the pore surface. A hydrophobic layer is formed on the surface of concrete and inside the pores near the surface; then it prevents concrete from ingress of water and aggressive ions.

Despite the valid feasibility and its function of protection in situ, quantitative techniques on the effectiveness of the surface treatment to assess functional properties have been rarely developed to date. In the general inspection of the concrete surface coating which is authorized by international standards, qualification items contain the thickness of the coating, cracks, and voids in concrete, adhesion of the coating, water absorption, the residual amount of agent, and freeze-thaw resistivity [9-13]. However, the presence inspection methods are limited to visual observation or very simple measurement; therefore, modification of cement matrix due to silane-based treatment agents in terms of enhancing resistance to ionic/molecular permeation cannot be assessed in detail. And about the porosity assessment, mercury intrusion porosimetry (MIP) or gas adsorption methods were often used [14-18] despite the limitation of sample preparation. For the sample preparation of those conventional methods, fragments of concrete should be collected under $5 \mathrm{~mm}$ of diameter and the sharp edges of the fragments must be removed to avoid crushing of fragile region during the $\mathrm{Hg}$ intrusion [19-21]. For this reason, there are limitations of obtaining accurate porosity of the surface coated zone and less percolated zone, as well as an unreacted zone, which could be varied depending on the means of the surface treatment. The properties and items to deal with the feasibility of the surface treatment were determined by earlier studies [22-25], including the ionic transport process through the treatment, durability, influence of substrate properties, service life, and economic expense.

In this study, the effect of surface treatment in lowering ionic transport, in terms of porosity, was evaluated by microscopic observation at the cover concrete with increasing the depths from the surface which previous studies did not try. As the agent for the surface treatment, the only silane-based agent was taken rather than siloxane and other agents due to its higher properties to protect concrete, as addressed in [23-25] and its common use in the market. Thus, a change in the porosity with cover depth was quantitatively measured to assess the degree of poreblocking or pore-lining. Considering the formation of phases in the pores at the nearer surface of the concrete substrate, the electrochemical impedance spectroscopy (EIS) was used to determine the barrier effect by expression into the polarization resistance. Simultaneously, the capability of chloride penetration in treated concrete was assessed in terms of diffusion coefficient and surface chloride ion concentration to interpret the feasibility of the surface treatment in evaluating the increased durability against chloride attack.

\section{Experiments}

2.1. Materials and Samples. Two different types of agents, which are commercially used products in the market, alkyl alkoxy silane-based liquid (Silane Liquid) and tetraethoxy silane-based crème (Silane Crème), were used to evaluate the effect of surface treatment against ionic/molecular transport into the concrete. Silane Liquid is a conventional hydrophobic agent, which penetrates into the treated surface and performs as a water repellent. Tetraethoxy silane is the main compound of Silane Crème, which can exhibit hydrophobic performance on the treated surface due to its base of alkoxy silane. Moreover, it is evident from the previous study that silane could show a pore filling effect by forming a silica gel on the pore surface [26]. Each molecular structure is shown in Figure 1.

Prior to the application of the agents, specimens were fabricated into a concrete, mortar, and paste on the purpose of each test to evaluate the performance of surface treatment agents. The mix proportion for cement, water, sand, and gravel was $1.00: 0.40: 2.46: 3.17$, respectively. For cement paste and mortar specimens, sand and gravels were removed in the mix proportioning from the above mix design. The ordinary Portland cement was used as a binder. All specimens demoulded after 24 hours from mixing were cured in a controlled chamber at $25 \pm 2^{\circ} \mathrm{C}$ and $60 \pm 5 \% \mathrm{RH}$ for 28 days; then the specimens were kept in an oven at $50 \pm 2^{\circ} \mathrm{C}$ for 24 hours to remove moisture in the concrete. The surface treatment was applied on the surface of fully dried specimens by spreading the agents for uniform distribution using a brush. And the specimens were further dried in a desiccator at the ambient temperature $\left(25 \pm 2^{\circ} \mathrm{C}\right)$ for 48 hours before testing.

2.2. Transport of Molecules and Ions. The effect of surface treatment in mitigating the water absorption was evaluated by monitoring the absorptivity of concrete specimens $\left(50 \mathrm{~mm}^{3}\right)$ which were followed by surface treatment as explained in Section 2.1. After measuring the original weight of dried specimens, the specimens were immersed in a water reservoir. Then, a change in the weight of the specimen was measured at $1,3,6,24,48,72,96$, and 168 hours of immersion, immediately after removing the surface water with a paper towel. The increased weight which was substituted from the original weight of dry specimen and subsequently expressed by percentage was taken as absorbed water content. The replication for each measurement was always five specimens and their average value was taken to the absorptivity assessment. 


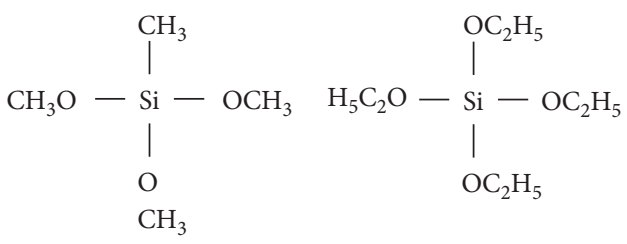

(a)

(b)

FIGURE 1: Chemical structure of (a) alkyl alkoxy silane and (b) tetraethoxy silane.

The resistance of surface treatment against chloride transport in concrete was evaluated by measuring the chloride profile using cylindrical concrete specimens $(\varnothing 100 \times 50 \mathrm{~mm})$. One end for each specimen was subjected to the surface treatment, and simultaneously the rest of the untreated surface was coated by epoxy resin so that chloride ions could only penetrate through one direction of the concrete. The specimens were immersed in a $4 \mathrm{M} \mathrm{NaCl}$ solution for 50 days to induce chloride ion penetration. For chloride profiling, the samples were ground from the surface with $5.0 \mathrm{~mm}$ increments using a diamond blade grinder. The collected dust sample was diluted in a nitric acid solution to extract chloride ions; then the diluted solution was taken to measure the concentration of chloride ions by cover depth using an ion-selective electrode. Once the chloride profile was obtained, the diffusion coefficient and surface chloride concentration were determined by solving Fick's 2nd law as given by

$$
C(x, t)=C_{s}\left(1-\operatorname{erf} \frac{x}{2 \sqrt{D_{t}}}\right),
$$

where $C(x, t)$ is chloride concentration at depth $x$ after time $t$ $\left(\% / \mathrm{m}^{3}\right), C_{\mathrm{s}}$ is surface chloride concentration $\left(\% / \mathrm{m}^{3}\right), x$ is depth $(\mathrm{mm}), D$ is the apparent diffusion coefficient $\left(\mathrm{m}^{2} / \mathrm{s}\right)$, and $t$ is a time of exposure (s).

\subsection{Microscopic and Electrochemical Observation. A modi-} fication of the pore structure in concrete arising from the surface treatment was observed by back-scattered electron (BSE) image analysis which is a substantially accurate method to determine porosity and degree of hydration [18, 27-29]. Cubic samples with cement paste $\left(10 \mathrm{~mm}^{3}\right)$ were fabricated and the surface treatments were applied on one side of the samples, assuming that aggregates do not affect pore distribution at the treated interface. To obtain BSE images containing the treated surface, the specimen was cut horizontally to the end plane using a diamond saw. After the drying process, a specimen that was impregnated with epoxy resin was vacuumed for more than 48 hours to be polished with silicon carbide paper of grit size 400-2400. The polished cross section was coated with platinum to increase electrical conductivity. The BSE image observation setting was at the accelerating voltage of $10 \mathrm{kV}$ and a working distance of $10 \mathrm{~mm}$. Twenty images were taken at each depth with $\times 500$ of magnification. To determine the porosity, the BSE images were binarized for pores; white pixels indicated pores and the other phases were converted to black. The number of pixels indicating the pores in the binarized image was counted to determine porosity. The size for each pixel accounted for $0.1058 \times 0.1058 \mu \mathrm{m}$, of which the size would be for the range of large capillary pore. The entire procedure for determining the porosity at the microscopic observation is rendered encompassing histogram of greyscale binarization and accounting for pixels of porosity, as given in Figure 2.

To determine ionic resistivity of the surface treatment, electrochemical impedance spectroscopy (EIS) was measured at mortar specimens $(\varnothing 50 \times 80 \mathrm{~mm})$. To complete the electric circuit, steel rebar $(\varnothing 10 \times 60 \mathrm{~mm})$ was located in the center of the mortar. In the process of demoulding, the protruded steel was covered with cement-rich paste, followed by attaching a heat shrink rubber band to prevent corrosion on the steel. After curing, surface treatment was applied on the lateral side of the specimen and the two ends of the bottom and top were coated by epoxy resin so that polarization could occur between the working and counter electrodes in the direction of the lateral side. The specimen was further cured for 56 days in saturated $\mathrm{Ca}(\mathrm{OH})_{2}$ solution to increase the electrical conductivity and reduce a leachingout of ions. The EIS was measured by a digital frequency response analyzer in conjunction with a potentiostat. Standard calomel electrode and carbon bar were set for the reference and counter electrode, respectively, where the steel rebar functioned for the working electrode. Then, the specimen was immersed in a $1 \mathrm{M} \mathrm{NaOH}$ solution. The amplitude of the sinusoidal voltage was chosen at $10 \mathrm{mV}$ r.m.s. and frequency was ranged from 0.1 to $100,000 \mathrm{~Hz}$. Ten points per decade were measured. The impedance response was interpreted by fitting an equivalent electrical circuit. The test set-up and the equivalent electrical circuit are given in Figure 3. The electrical behavior of the steel was represented by a parallel connection of polarization resistance $\left(R_{\mathrm{p}}\right)$ and double-layer capacitance $\left(C_{\mathrm{f}}\right)$. Since the steel was considered as being passivated, the steel surface was simulated to a single coating capacitance $\left(C_{\mathrm{c}}\right)$, representing the steelmortar interface of hydration products. The pore resistance $\left(R_{\mathrm{c}}\right)$ and surface resistance $\left(R_{\mathrm{s}}\right)$ dealt with the pore matrix in mortar specimen and the treated surface, respectively.

\section{Results}

3.1. Permeability and Diffusivity. The water absorption of concrete under surface treatment was monitored for 168 hours ( 7 days) after immersing the specimen in water by determining the ratio of absorbed water from the weight of the dried specimen. It is evident that surface treatment 

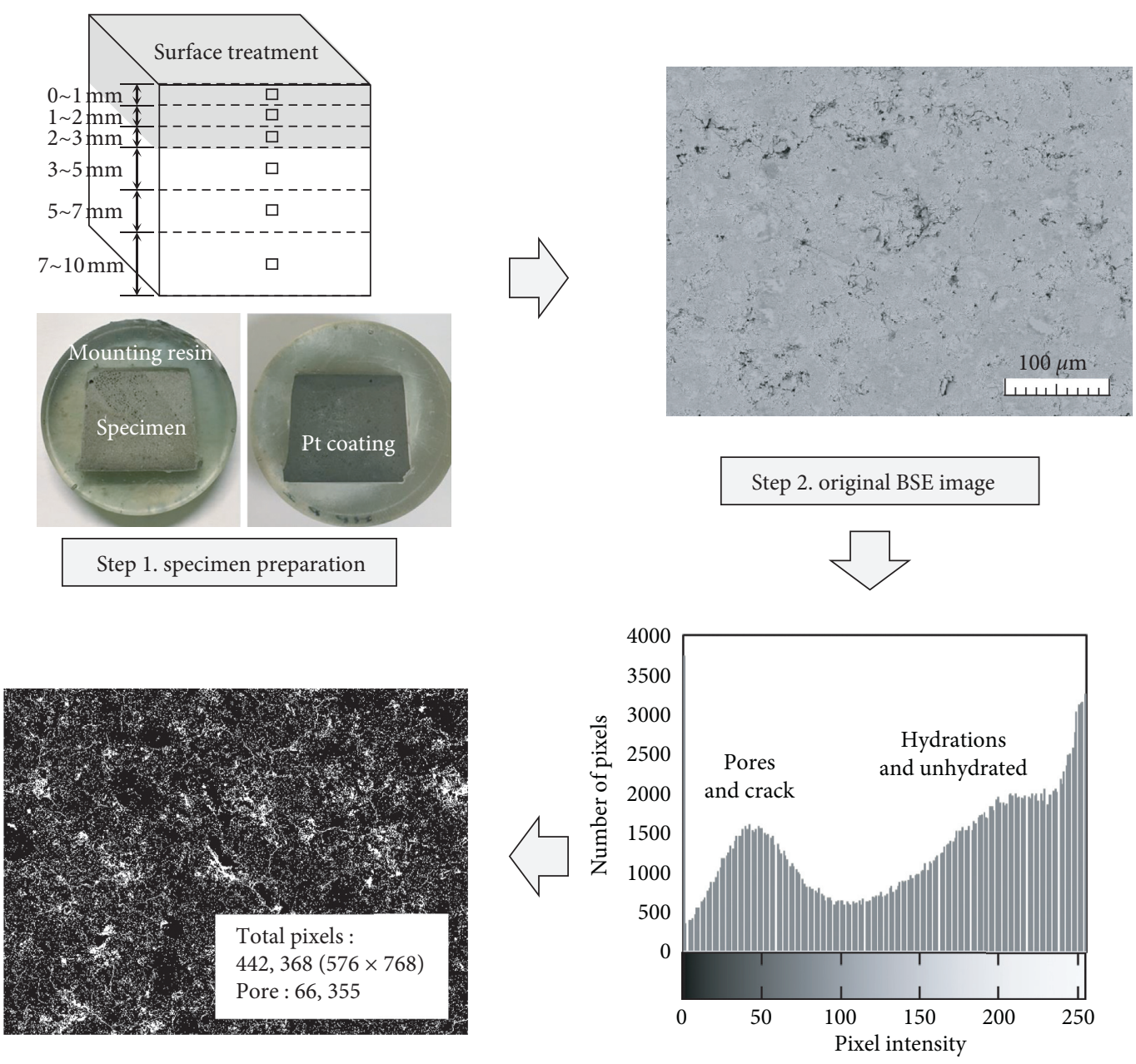

Step 4. pore thresholding

Step 3. pixel intensity analysis

Figure 2: Process of BSE image analysis.

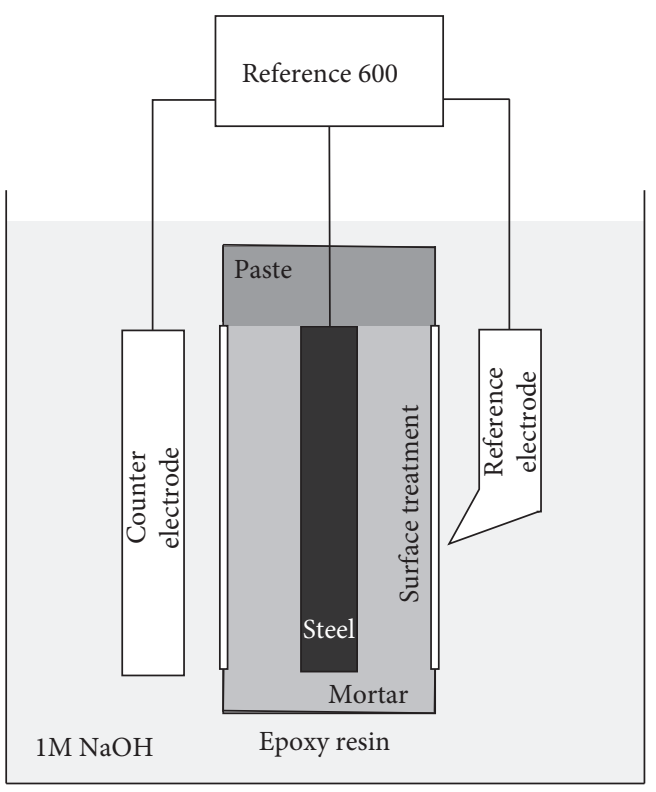

(a)

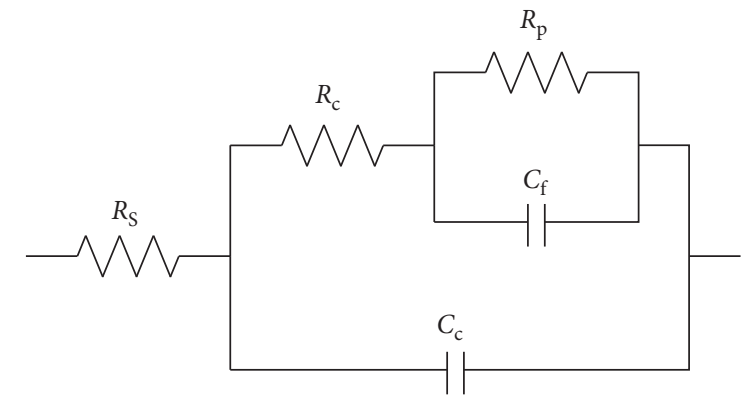

$R_{\mathrm{p}}:$ Polsrisation resistance $(\Omega)$

$C_{\mathrm{f}}$ : Double layer capacitance $(\mathrm{F})$

$R_{\mathrm{c}}$ : Pore resistance $(\Omega)$

$C_{\mathrm{c}}$ : Coating capacitance $(\mathrm{F})$

$R_{\mathrm{S}}$ : Surface resistance $(\Omega)$

FIGURE 3: Set-up and equivalent electrical circuit for EIS measurement. 
helped in lowering the water absorptivity irrespective of types of the treatment as given in Figure 4. For both surface treatments, the absorption of water ranged about $2.0 \%$ more or less by weight of the dried specimen; Silane Liquid treatment accounted eventually for $2.3 \%$ of water absorption and Silane Crème for 1.6\%. In particular, after 96 hours of immersion, the absorption ratio was mostly converged, whilst the water absorption rapidly proceeded for the first 24 hours. For untreated specimen, the water absorption was converged from 48 hours of immersion, in which the values substantially accounted for $6.0 \%$ at 168 hours. Both surface treatments were effective in mitigating water absorption, due to the lining of the hydrophobic layer on the concrete surface. Silane Crème shows further inhibitive performance against water permeation, presumably arising from the poreblocking effect. In fact, the Silane Crème treatment more easily penetrated the pores on the surface of concrete during the treatment of spreading and then blocked the pore walls in terms of pore-lining. For Silane Liquid treatment, the pore-blocking is, however, limited at the very front of inner concrete. Thus, the resistance for the Silane Liquid treatment to ionic/molecular transport could be formed in the vicinity of the very front surface, presumably leading to a reduction of the build-up of external ions but the effect might be less than the Silane Crème.

The resistance of surface treatment against ionic/molecular transport was evaluated by chloride profiling of concrete which was submerged in saltwater. Because chloride transport was driven by only one directional diffusion, the apparent diffusion coefficient and surface chloride concentration were simultaneously determined by using chloride ingresses at different depths for a certain duration of immersion. As seen in Figure 5, the concentration of chloride was reduced with the depth of cover concrete, irrespective of whether or not the surface treatment was applied. In particular, the chloride ingress was mostly nullified at increasing the depth beyond $15.0-20.0 \mathrm{~mm}$ from the concrete surface for all specimens due to the limited duration of immersion in the saltwater. The surface treatment had benefits in lowering the chloride ingress at all depths, resulting from a reduction of the surface chloride concentration and thus diffusivity of chloride ions. For Silane Liquid treatment, there was a significant reduction of the surface chloride, accounting for $1.32 \%$, whilst untreated specimen produced an even higher range of about $2.49 \%$. Substantially, the Silane Liquid treatment produced a lower diffusion coefficient. Silane Crème treatment had also a reduction of the surface chloride in the range of $2.30 \%$. Moreover, a reduction of the apparent diffusion coefficient was remarkably large; the apparent diffusion coefficient for untreated Silane Liquid and Silane Crème treatments was $9.17 \times 10^{-12}, 8.05 \times 10^{-12}$, and $2.98 \times 10^{-12} \mathrm{~m}^{2} / \mathrm{s}$, respectively. The further reduced value of the apparent diffusion coefficient for Silane Crème treatment may arise from the porelining effect as well as pore-blocking effect. In fact, Silane Liquid treatment was more effective in forming the hydrophobic layer in the vicinity of the very front surface of concrete cover and showed highly water repellent characteristic, leading to a significant reduction of the surface

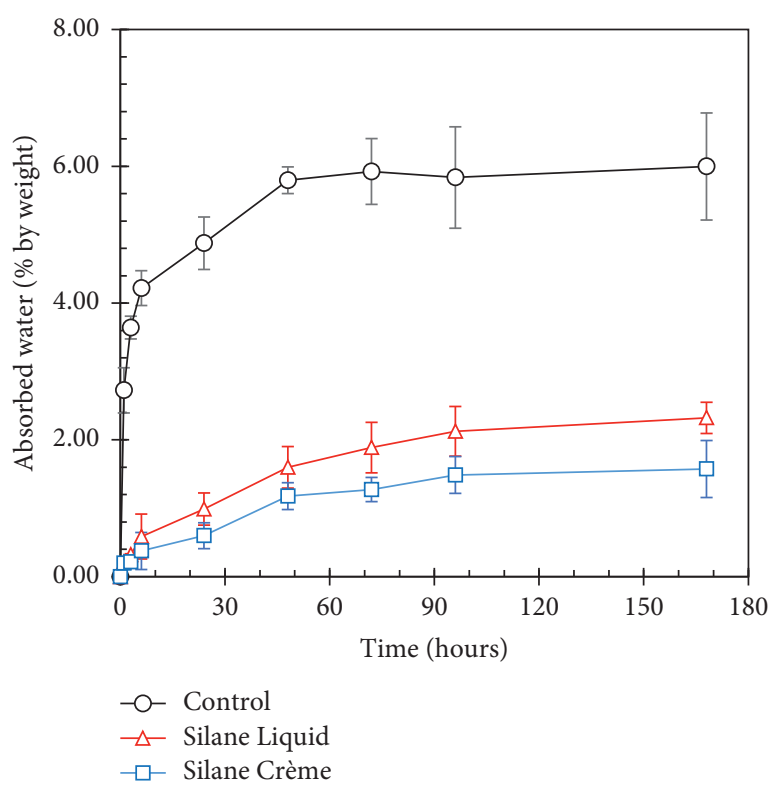

FIGURE 4: Water absorption of concrete at surface treatment of SS liquid and SS crème.

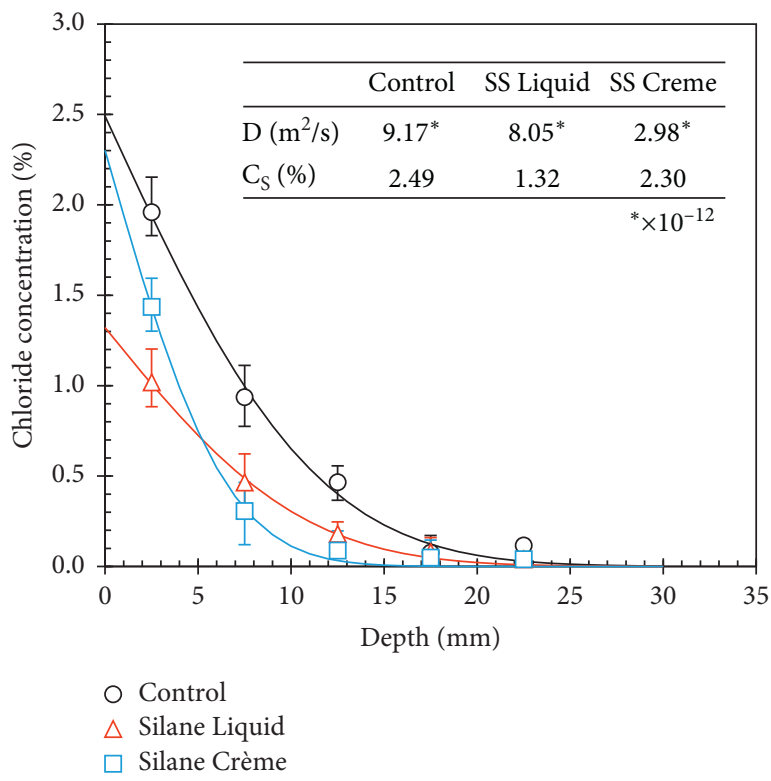

FIGURE 5: Chloride concentration profiles in concrete for surface treatment.

chloride, but only a marginal reduction of the chloride diffusivity was achieved. However, Silane Crème treatment had an effect of the pore-blocking in inner pores, so that the chloride ingress could be sharply decreased at the inner depth, imposing a significant reduction of the diffusivity of chloride ions in turn. The marginal reduction of surface chloride arose from the impregnation of Silane Crème, resulting in a build-up of chloride inside the surface.

3.2. Modification of Porosimetry. To quantify the distribution of porosity with depth, the BSE image of cement paste 
specimens at the surface treatment applied interfacial region from the surface to $10.0 \mathrm{~mm}$ of the cover depth was obtained. At each depth, 5 representative BSE images and their binarized images for porosity are given together with the porosity ratio for each image as given in Figure 6. It is seen that the fraction for porosity which was calculated from binarized BSE images was strongly dependent on the depth and types of surface treatment. For untreated specimens, it seems that there was a marginal variation in the porosity regardless of the depth. However, treated specimens produced different levels of porosity for depth variation; an increase in the cover depth resulted in an increase in the porosity; in another word, the porosity of cement matrix in the vicinity of the surface was reduced compared to the control group. It might be postulated that the surface treatment agents could fill up the pores in the vicinity of the concrete surface. In fact, hydrophobic agents for the surface treatment could block the pores by water repellent characteristics, more or less reducing the porosity, thereby increasing the resistance to ionic/molecular transport.

To quantify the effect of surface treatment in reducing pores, the porosity from the surface of the specimen was calculated at each depth and then the distribution of porosity was depicted in Figure 7. It is evident that the specimens under the surface treatment produced lower porosity at the nearer surface, below $5.0 \mathrm{~mm}$ of the cover depth, while the untreated specimen was indicative of the higher porosity at all depths, accounting for about 5.2\%. Especially, Silane Crème treatment achieved a significant reduction of the porosity at the very front of the inner specimen. For example, at the nearer surface $(<1.0 \mathrm{~mm})$, the porosity of the specimen was lower than $0.5 \%$, which was gradually increased with depth up to $5.0 \%$ at $6.5 \mathrm{~mm}$ of the cover depth. It suggests that the Silane Crème could modify the pore structure, in particular, at the nearer surface, which could, in turn, reduce the capability of external ions for penetration, imposing the increased resistance to ionic/molecular transport in treated concretes. In the present study, the margin for the pixel in the BSE image is equivalent to the size of the small capillary pore. Thus, the distribution of porosity could more directly reflect chloride transport in concrete, considering that the rate of chloride transport is usually dependent on the fraction of capillary pores. It is notable that Silane Liquid treatment also showed a reduction of the porosity at the surface up to about $4.0 \mathrm{~mm}$, thereby leading to a dramatic reduction of the surface chloride when the specimen was immersed in salt solution though it was less than Silane Crème.

\subsection{Electrochemical Resistance of Surface Treatment. The} electrochemical behavior of mortars with the surface treatment was evaluated by measuring the AC impedance of embedded steel, as given in Figure 8 in the form of (a) Nyquist and (b) Bode diagram. The impedance spectrum was interpreted by fitting on the equivalent electrical circuit, and the elements of the circuit were subsequently determined. From the Nyquist plot, the resistance element can be estimated through the diameter of the semicircle formed by the fitting curve. As the specimens were exposed to the corrosion-free condition, the high polarization resistance was achieved, irrespective of the surface treatment, accounting for $19.7,26.1$, and $19.8 \mathrm{k} \Omega$ for untreated Silane Liquid and Silane Crème treatments, respectively. The maximum frequency value, at which the maximum change of phase angle occurs, was used to determine the capacitance value, using

$$
C_{\mathrm{f}}=\frac{1}{\omega_{\max } \times R_{\mathrm{p}}},
$$

where $C_{\mathrm{f}}$ is for the double-layer capacitance, $\omega_{\max }$ is the maximum frequency, and $R_{\mathrm{p}}$ is the polarization resistance, respectively. The capacitance of the double-layer indicated similar values ranging from 1.81 to $2.34 \mathrm{mF}$, reflecting the passivated condition of embedded steel.

Similarly, the coating capacitance $\left(C_{c}\right)$ ranged, irrespective of the surface treatment, from 38.9 to $52.8 \mathrm{nF}$, but the electrical resistance for concrete including the pore resistance $\left(R_{\mathrm{c}}\right)$ and surface resistance $\left(R_{\mathrm{s}}\right)$ obviously increased when applying the surface treatment. For example, the surface resistances for treated specimens accounted for 182.7 and $203.9 \Omega$ for Silane Liquid and Silane Crème treatments, respectively. It suggests that the surface resistance may arise from the hydrophobic property of the surface treatment, which could interrupt the electrical conduction at the surface of the concrete. Silane Crème treatment indicated higher pore resistance than untreated and Silane Liquid treatment, presumably due to the pore filling effect.

\section{Discussion}

4.1. Types of Surface Treatment. The surface treatment is often preferred to enhance the serviceability of concrete structures subjected to chemical degradation such as chloride-induced corrosion, sulfate attack, and carbonation, due to its easy application and the effectiveness in hindering external aggressive ions from percolating into concrete with no damage of cover concrete. Coating and sealing concrete surfaces were initially developed for the surface treatment, in which the technique forms continuous polymer layer on the surface of the substrate. For example, epoxy resin-, acrylic-, and polyurethane-based polymeric materials have been widely used. In particular, the polyurethane coating was very promising in resisting the penetration of chloride ions [30]. However, its application is currently quite limited in situ, because the hardened layer on treated surface is often blistered off with time and weathering, thereby being followed by regular restorations of the treatment. In terms of the application to the concrete surface, the polymeric layer could be dissolved in the alkaline pore solution leached from the concrete body, leading to the accelerated process of blistering-off. For the restoration of blistered parts, retreatment is essential but mostly restricted in aerated parts of concrete structures; it is mostly impossible for aquaticimmersed parts of concrete to apply the retreatment. Thus, pore-blocking agents have been alternatively developed. The inorganic agents, such as silicate-based solution, react with 


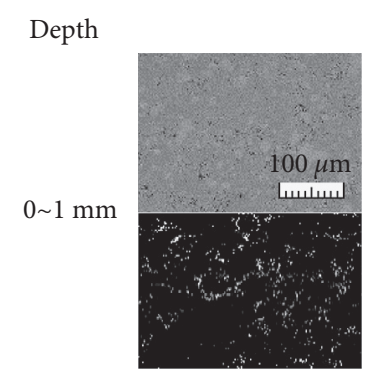

$5.40 \%$

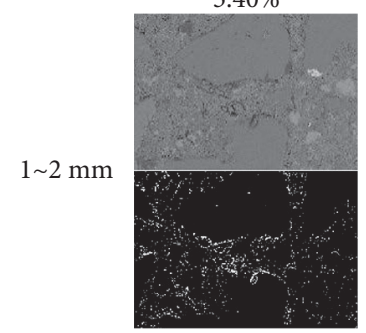

$5.30 \%$

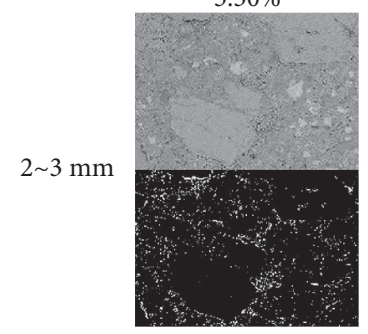

$4.82 \%$

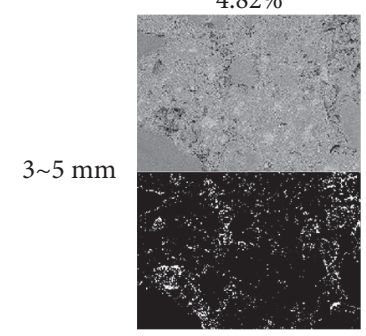

$5.10 \%$

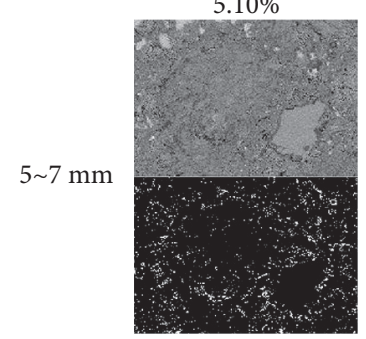

$5.19 \%$

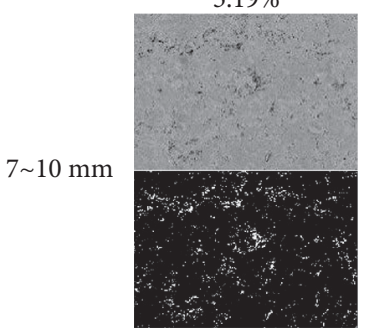

$5.21 \%$

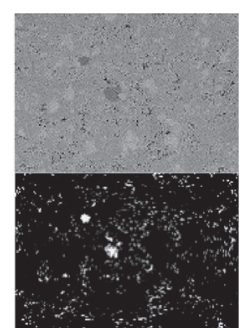

$5.06 \%$

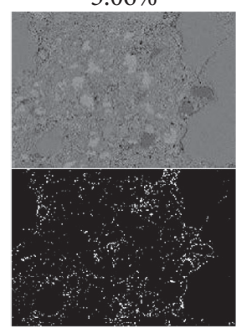

$5.17 \%$

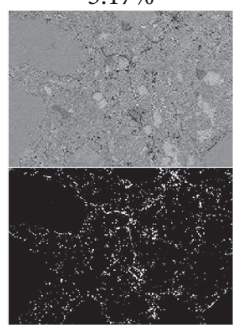

$4.95 \%$

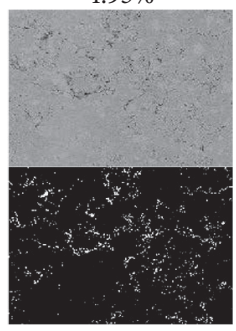

$5.21 \%$

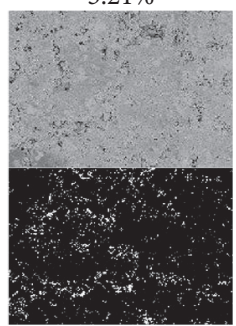

$5.07 \%$

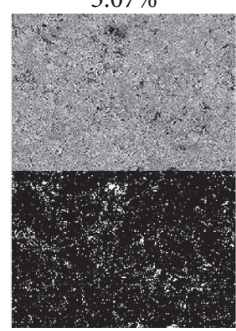

$5.33 \%$

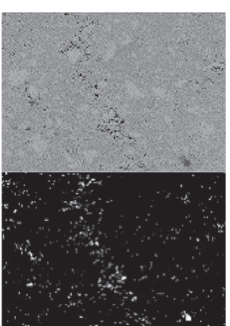

$5.23 \%$

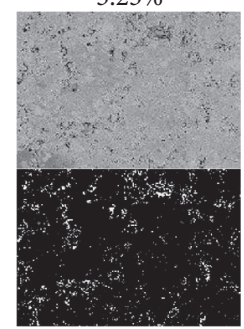

$5.05 \%$

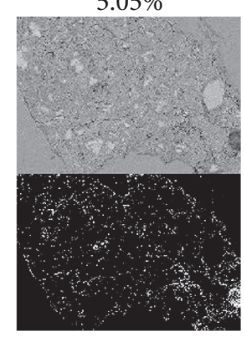

$5.04 \%$

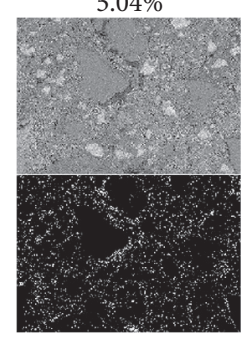

$5.00 \%$

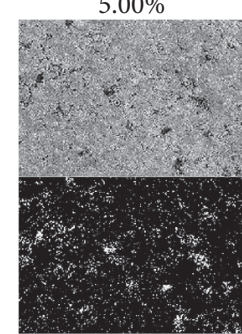

$5.20 \%$

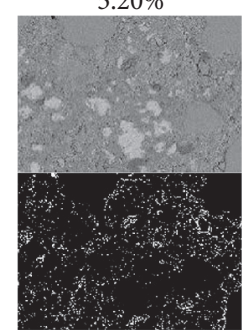

$5.16 \%$

(a)

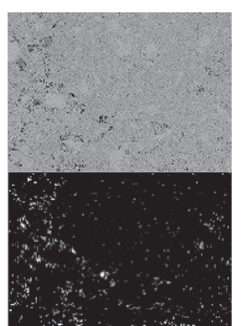

$5.04 \%$

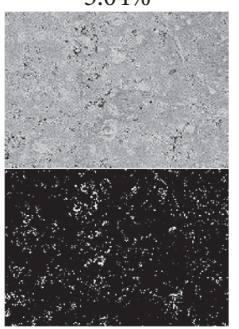

$5.18 \%$

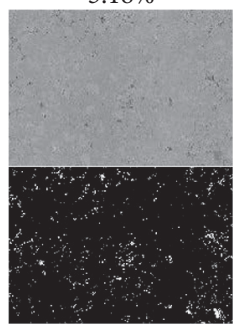

$4.98 \%$

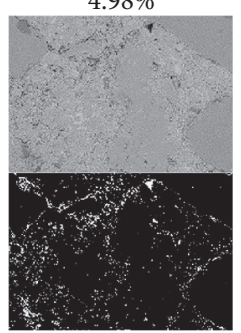

$5.36 \%$

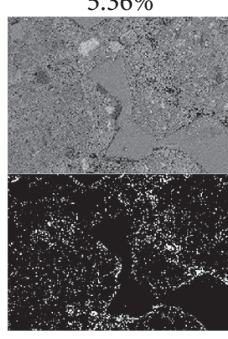

$5.07 \%$

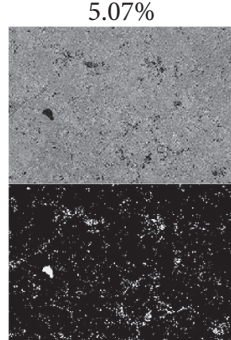

$5.42 \%$

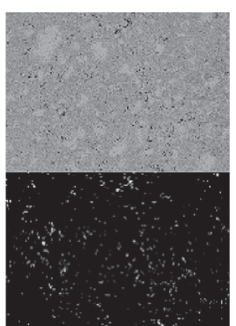

$5.18 \%$

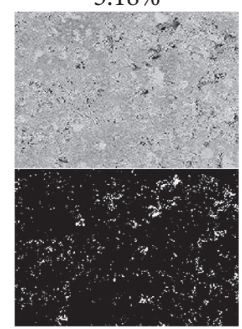

$5.03 \%$

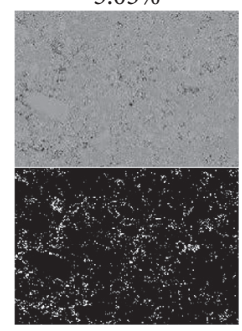

$5.20 \%$

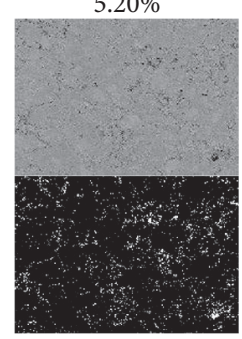

$5.35 \%$

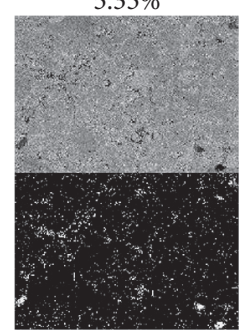

$5.14 \%$

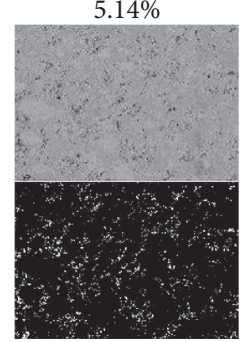

$5.32 \%$

Figure 6: Continued. 


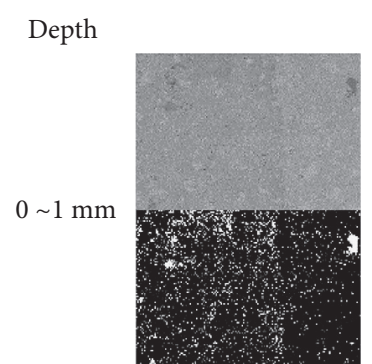

$1.32 \%$

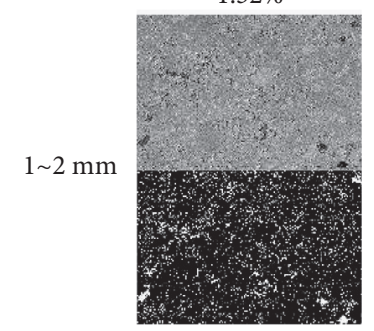

$2.04 \%$

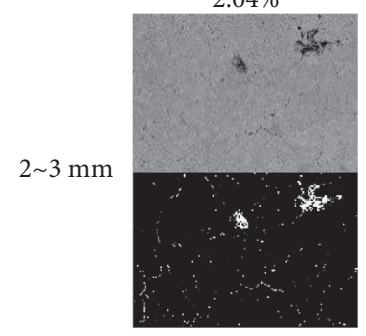

$4.23 \%$

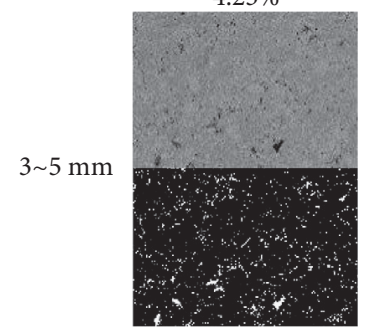

$5.01 \%$

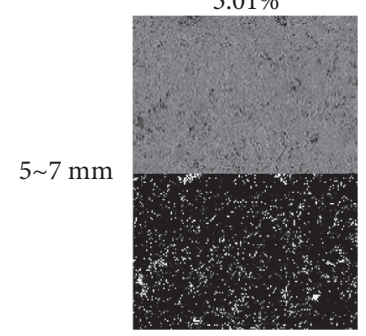

$4.98 \%$

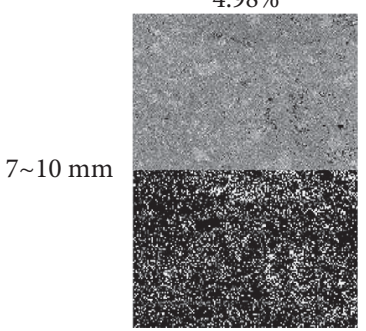

$5.60 \%$

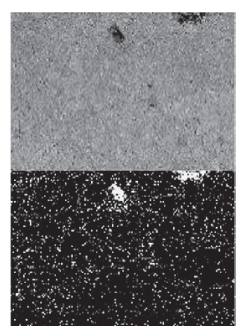

$1.12 \%$

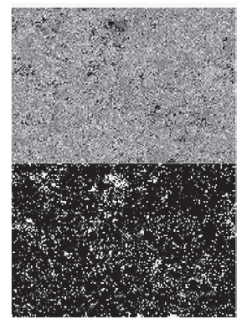

$2.43 \%$

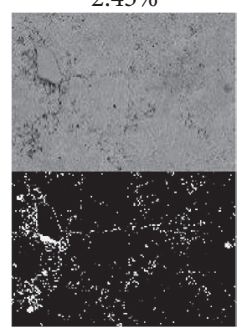

$3.98 \%$

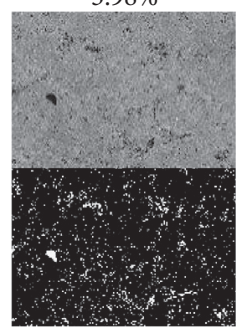

$5.01 \%$

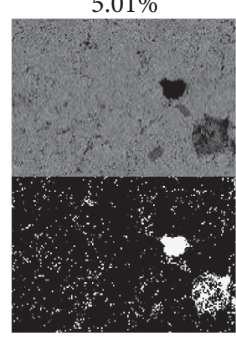

$5.00 \%$

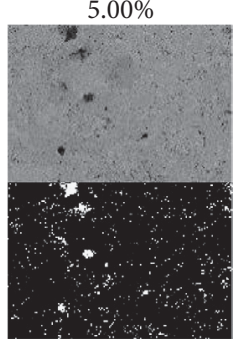

$5.04 \%$

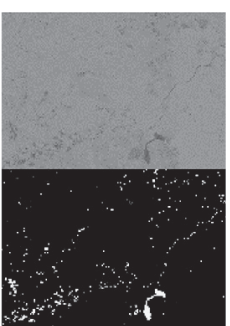

$1.03 \%$

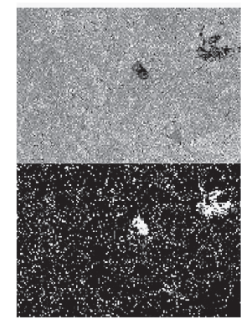

$2.71 \%$

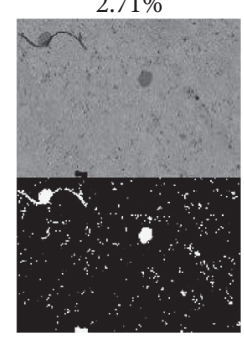

$4.03 \%$

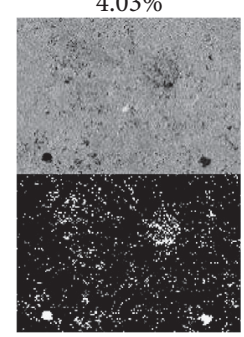

$4.82 \%$

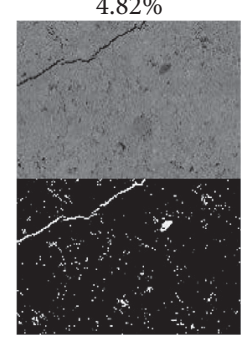

$4.94 \%$

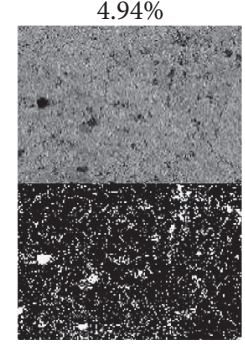

$5.27 \%$

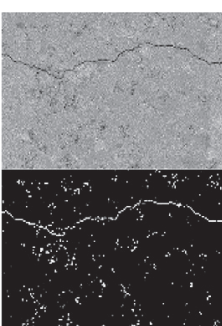

$0.89 \%$

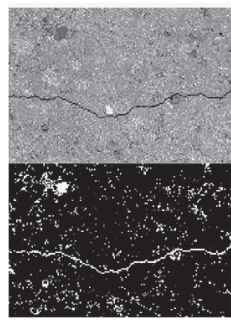

$2.53 \%$

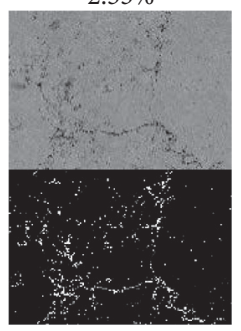

$3.83 \%$

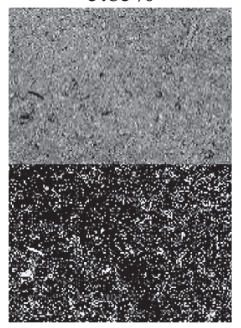

$5.36 \%$

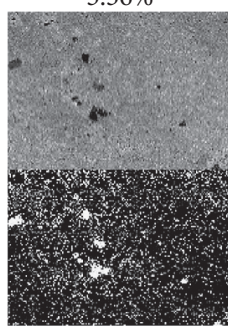

$4.55 \%$

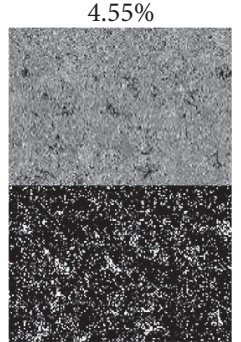

$5.77 \%$

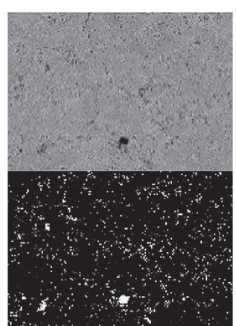

$0.84 \%$

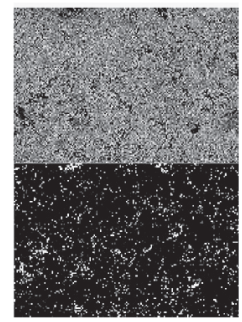

$2.44 \%$

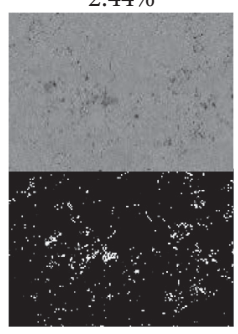

$4.30 \%$

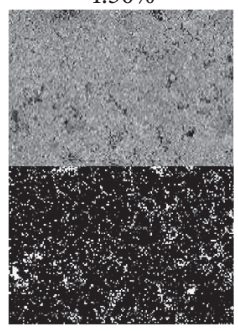

$5.35 \%$

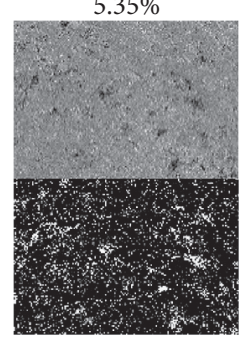

$4.72 \%$

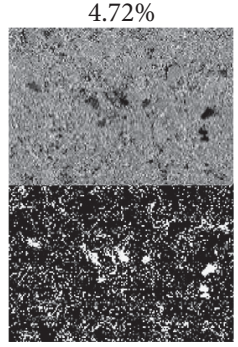

$5.46 \%$

(b)

Figure 6: Continued. 

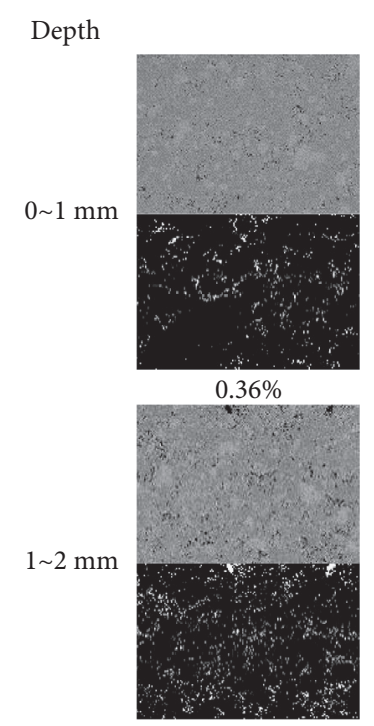

$1.07 \%$

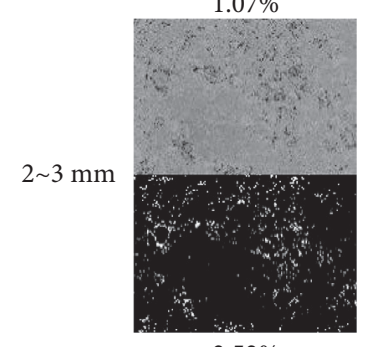

$2.52 \%$

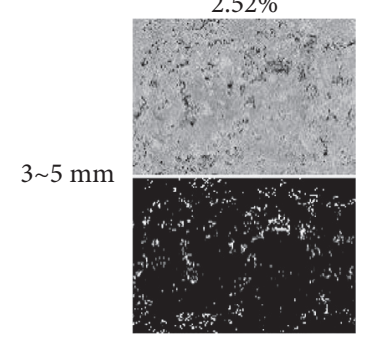

$3.71 \%$

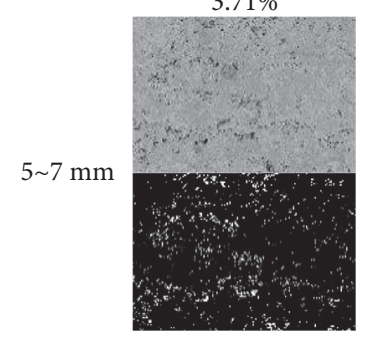

$5.46 \%$

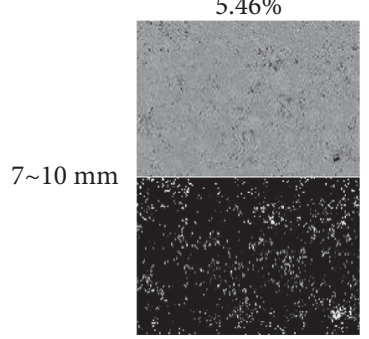

$5.16 \%$

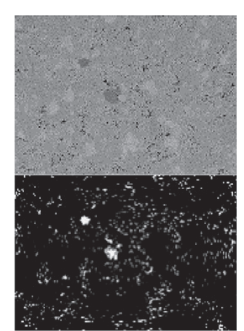

$0.11 \%$

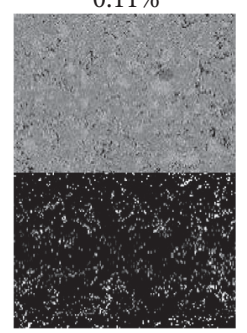

$0.93 \%$

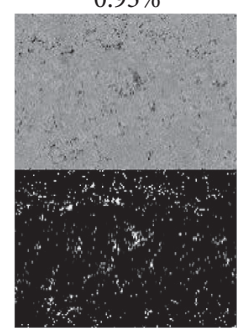

$1.98 \%$

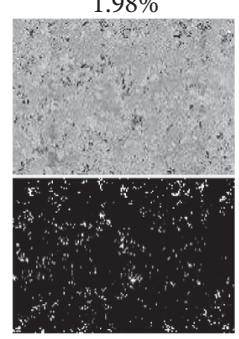

$4.29 \%$

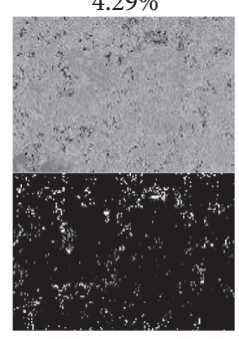

$4.29 \%$

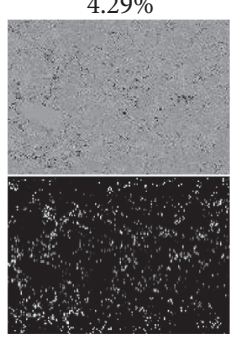

$5.93 \%$

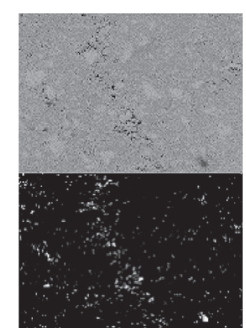

$0.35 \%$

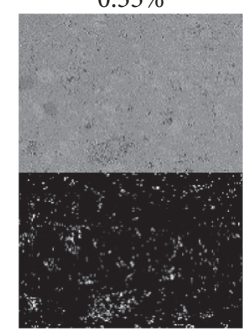

$1.17 \%$

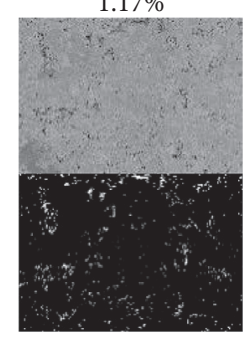

$2.28 \%$

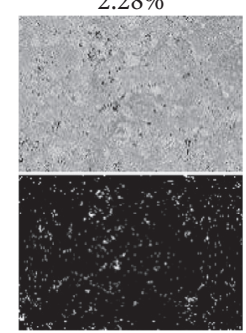

$4.51 \%$

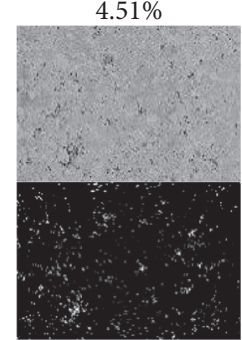

$4.28 \%$

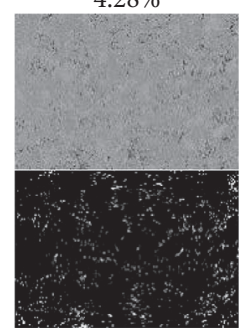

$5.83 \%$

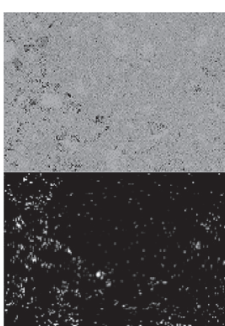

$0.04 \%$

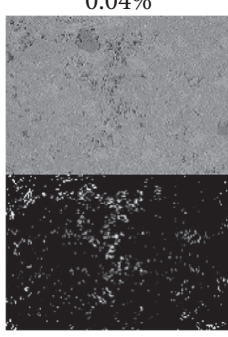

$1.02 \%$

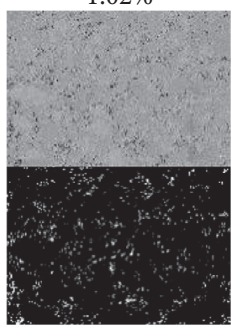

$2.16 \%$

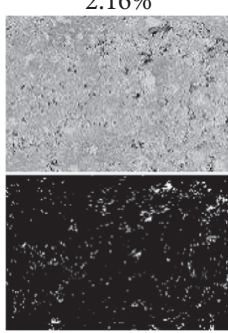

$3.78 \%$

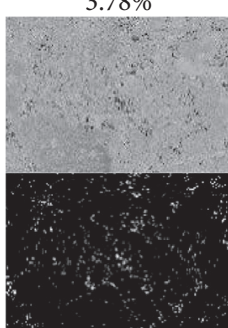

$5.90 \%$

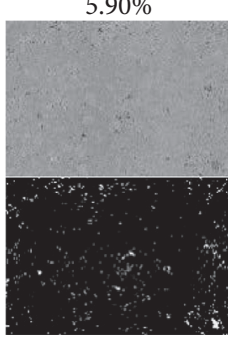

$5.00 \%$

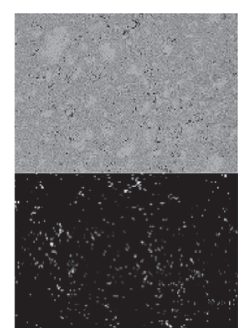

$0.48 \%$

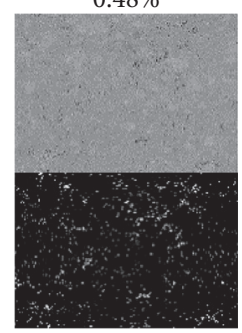

$1.75 \%$

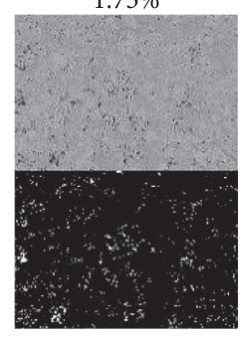

$2.46 \%$

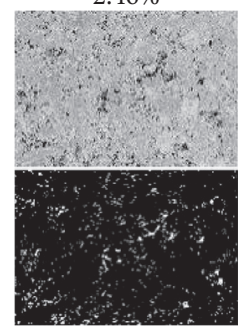

$3.77 \%$

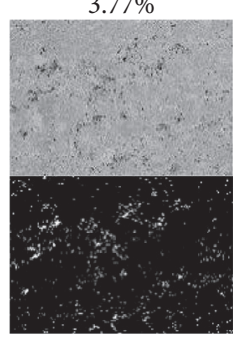

$5.00 \%$

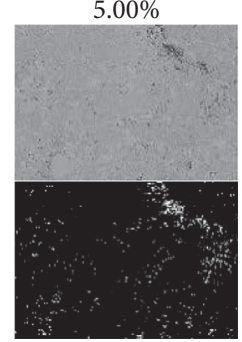

$5.16 \%$

(c)

FIGURE 6: Representative original and binarised BSE images at incrementally different depths from treated surface for (a) control, (b) Silane Liquid, and (c) Silane Crème together with porosity ratio (percentage). 


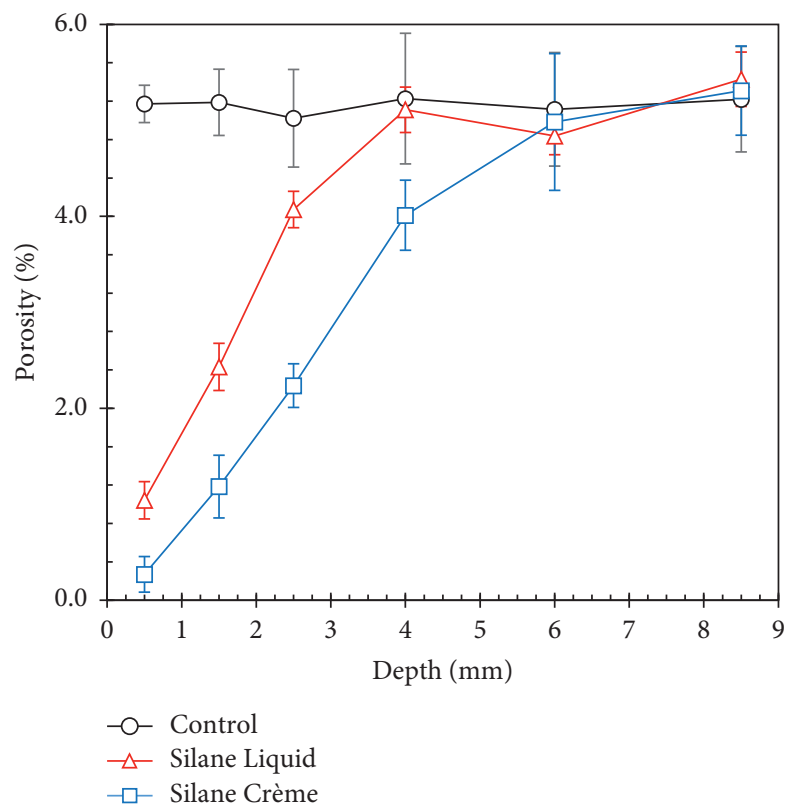

FIGURE 7: Porosity distribution from treated surface for the surface treatment determined by the BSE image analysis.

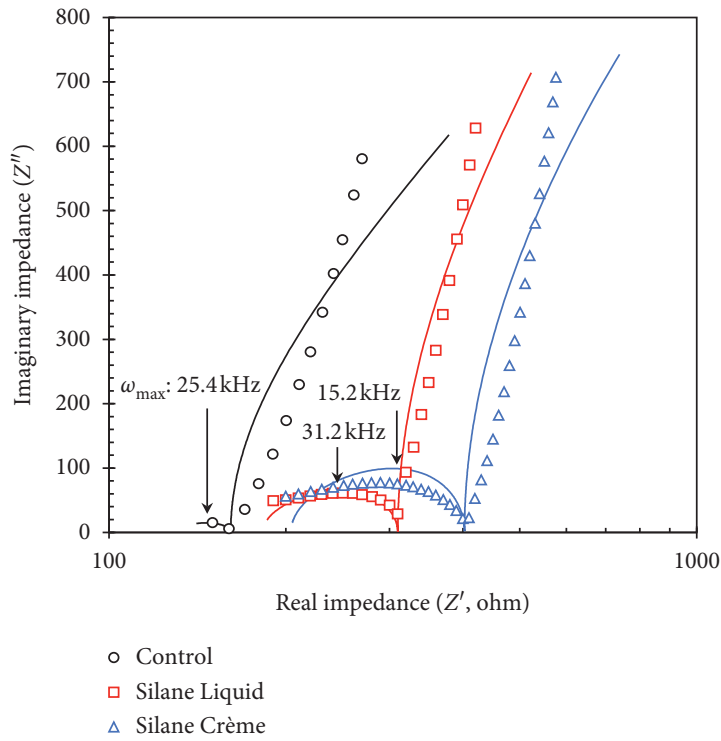

(a)

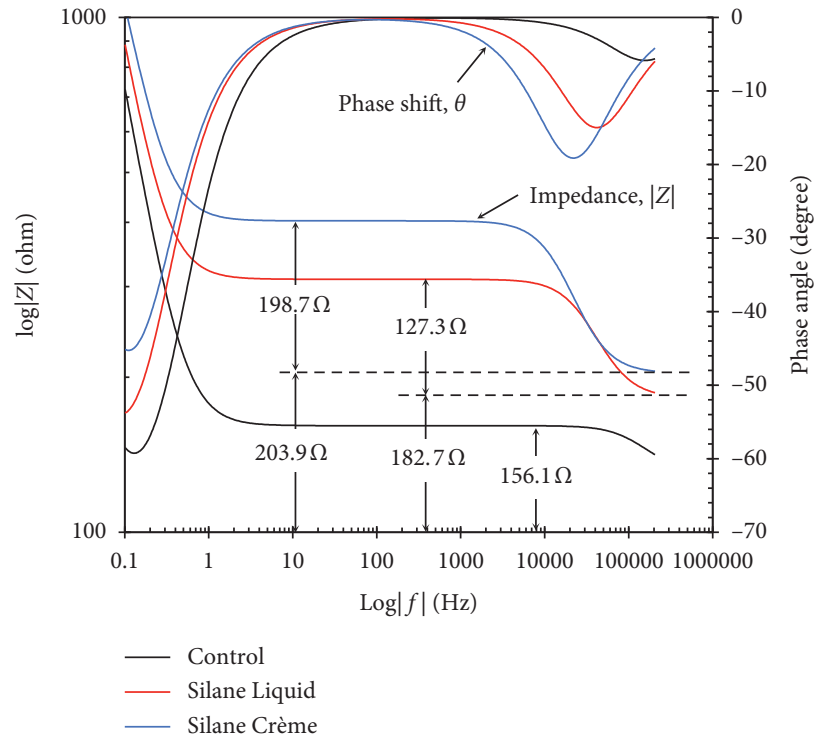

(b)

FIgURE 8: Electrochemical impedance response expressed by (a) Nyquist plot and (b) Bode diagram for the surface treatment.

soluble hydrates in concrete and then insoluble hydrates are substantially formed and then refine the pore structure of concrete [31]. The compatibility of pore blockers must be, however, secured for the reaction between the agent and hydration products, which might otherwise accompany an overwhelming formation of hydrates in the pores at the nearer surface of concrete, leading to a generation of the micro-cracking along with the pore network.

More currently, water repellent agents are widely used for surface treatment, which usually allows vapor to be mobile in the pores but prevent water molecules from penetrating into concrete. This effect is attributed to a modification of the pore structure, shifting to the smaller pore size in distribution. Once a water repellent agent penetrates into concrete, hydrophobic blocking line is formed through the pore wall, the so-called pore-lining. Thus, for the surface treatment to be effective for lining the pore walls, the pore distribution must be stably formed, imposing that mature concrete may be more beneficial in the surface treatment rather than early-age concrete [32]. The water repellent-based pore-lining agents often consist of silane and siloxane, which subsequently form in different 
types: gel, crème, and liquid. When it comes to the effectiveness, crème type is the most penetrable in concrete, subsequently forming the longer lining in the pore wall [33]. In turn, the crème type treatment could be more resistant against external molecules. In the present study, the crème type agent was effective in reducing the porosity in the deeper range at the surface of concrete, compared to liquid type treatment. Substantially, there was a dramatic reduction of chloride ingresses, in terms of the chloride diffusivity, when concrete treated with the crème type agent was immersed in saltwater as it has multifunction of pore-lining and pore-blocking. Despite the lower viscosity, liquid type treatment had quite a limited range of penetration into the concrete. It may be attributed to a lower reactivity with hydrates and to its vaporization in the process of applying the surface treatment and limited pore-lining for protection, for example, brushing or/and spraying agents on the concrete surface.

Key implementation in applying the surface treatment is to secure the penetration depth of hydrophobic agent into concrete $[34,35]$, associated with long-lasting feasibility of the treatment effect. As seen in the present study, its penetration depth was, however, limited to $4.0-6.0 \mathrm{~mm}$, considering the distribution of the porosity in the vicinity of the concrete surface. For crème and gel type agents, the treatment process is quite primitive: brushing directly on the concrete surface would, in fact, potentially impose the physical-demanding labor and time-consuming process. Despite the difficulty in the treatment process, crème and gel type agent could be effective in the surface treatment, except for the penetration depth, in that their treatments are usually more resistant to harsh weathering, ultraviolet radiation, and blistering-off [35]. In the present study, the increased surface resistance of the crème type agent to external aggressive molecules and ions was confirmed by the EIS, producing the higher impedance and capacitance. Substantially, the surface treatment is effective in resisting ionic transport to concrete, depending on types of surface treatment. Thus, the selection of the surface treatment type must be considered for its feasibility and economic benefit. It is additionally notable that the surface treatment may not be expected to arrest generation of concrete cracking and its further propagation, in which the phenomenon always occurs irrespective of whether or not the surface treatment is applied on the concrete surface $[33,36]$. It implies that the benefits of surface treatment could be fully achieved only in sound concrete since the hydrophobic agents could cover up the pores and voids in the limited range and size.

4.2. Durability and Performance. The benefit of surface treatment would arise from preventing ionic transport from an external environment such as marine and sewer conditions. In particular, the surface treatment has been widely used to protect the concrete structures exposed/submerged in a marine environment, which would impose the risk of chloride-induced corrosion of steel in concrete. As the surface treatment prevents chloride ions from penetrating inner concrete, the rate of chloride transport would be expected as nullified, as being free from the risk of chlorideinduced corrosion [37, 38]. However, in the present study, the surface treatment could mitigate chloride transport in terms of lowering a build-up of the surface chloride or/and reducing the rate of chloride diffusion in concrete, depending on types of surface treatment. Substantially, the surface treatment could achieve a preventive measure against corrosion of steel by a reduction of chloride transport. However, its effect has not been quantified in predicting corrosion-free life. In predicting the service life, chloride transport and corrosion resistance of steel are mutually key factors. Also, it is notable that these preventive techniques affect both rate of chloride transport and corrosiveness of steel. Unlike conventional preventive measures such as a modification of concrete mix design using ground granulated blast furnace slag or/and silica fume at a lower $\mathrm{W} / \mathrm{C}$, the surface treatment does not modify the corrosiveness of steel in concrete, imposing that only the rate of chloride transport could be mitigated at a given corrosion resistance in concrete.

Moreover, the surface treatment could enhance the resistance of steel to corrosion by suppressing the cathodic reaction on the steel surface [39]. As seen in the present study, surface treatment could prevent water molecules from percolating into the concrete body. Thus, the concentration of water and oxygen could be reduced in inner concrete, leading to a reduction of cathodic reactivity on the steel surface. To initiate corrosion in concrete, the concentration of water molecules in the vicinity of the steel must be secured, which could subsequently form $\mathrm{Fe}(\mathrm{OH})_{2}$ with no chloride reaction, followed by $\mathrm{Fe}(\mathrm{Cl})_{2}$ and rust on the steel surface. However, the surface treatment can reduce the mobility of water and gas and then reduce the possibility of cathodic reaction on the steel. Even after the onset of corrosion, the surface treatment could delay the corrosion process in terms of its propagation, due to the limited concentration of water and oxygen. Due to restricted access of water and oxygen into the concrete body, the surface treatment could enhance the resistance to concrete deterioration in terms of chemical degradation such as sulfate attack and carbonation [40]. However, a lower bond between concrete body and surface treatment may potentially induce lower frost damage and abrasion resistance [41].

\section{Conclusion}

In this study, the surface treatment with Silane Liquid and Silane Crème on the concrete surface was investigated on their resistance against external ionic/molecular penetration. To quantify their resistance, the EIS behavior was measured to express the polarization resistance, and the porosity at the nearer surface of the concrete was simultaneously quantified by using the BSE image segmentation in depth. Chloride profiling for the treated concrete immersed in saltwater was used to assess the resistance to chloride transport. The conclusion obtained from these experimental works is given as follows.

(1) The surface treatment with Silane Liquid and Silane Crème could enhance the resistance to ionic 
transport. Both treatments could achieve the lower water absorption and simultaneously the lower rate of chloride transport in the concrete substrate, arising from a reduction of the surface chloride concentration and chloride diffusivity. In particular, the Silane Liquid treatment could reduce a large margin of the surface chloride, whilst the Silane Crème treatment significantly lowered the apparent diffusion coefficient for chloride ions in concrete.

(2) From the AC impedance measurement at the concrete surface subjected to the surface treatment, it was found that the surface treatment could increase the polarization resistance at the concrete surface at a mostly given concrete resistance, implying that the concrete substrate could, in turn, achieve the increased barrier effect resulting in higher resistance to externally aggressive ion penetration.

(3) From the porosity assessment by BSE image segmentation analysis, pore blocking was predominantly observed within $5.0 \mathrm{~mm}$ from the concrete surface where coating was applied, and the crème type showed much reduction of the porosity compared to liquid type until $5 \mathrm{~mm}$. The porosity at the first $1 \mathrm{~mm}$ of the surface treated specimen accounted for $0.5-1.0 \%$ and gradually converged to the original specimen porosity (about $5 \%$ ). It seems that a reduction of the porosity at the concrete surface could potentially mitigate the ionic transport into the concrete substrate, thereby enhancing the resistance to the chemical degradation of concrete.

\section{Data Availability}

The data used to support the findings of this study are included within the article.

\section{Conflicts of Interest}

The authors declare that there are no conflicts of interest regarding the publication of this article.

\section{Acknowledgments}

This work was supported by Korea Institute of Energy Technology Evaluation and Planning (KETEP) and the Ministry of Trade, Industry, and Energy (MOTIE) of the Republic of Korea (no. 20193210100050).

\section{References}

[1] K. Y. Ann, H. S. Jung, H. S. Kim, S. S. Kim, and H. Y. Moon, "Effect of calcium nitrite-based corrosion inhibitor in preventing corrosion of embedded steel in concrete," Cement and Concrete Research, vol. 36, no. 3, pp. 530-535, 2006.

[2] K. Y. Ann and N. R. Buenfeld, "The effect of calcium nitrite on the chloride-induced corrosion of steel in concrete," Magazine of Concrete Research, vol. 59, no. 9, pp. 689-697, 2007.

[3] N. R. Buenfeld and J. P. Broomfield, "Influence of electrochemical chloride extraction on the bond between steel and concrete," Magazine of Concrete Research, vol. 52, no. 2, pp. 79-91, 2000.

[4] L. A. Maldonado, P. Castro, J. H. Marrufo, W. Gonzalez, and A. Zapata, "Bond loss between epoxy and alkyd coated reinforcement rebar and concrete," in Corrosion Forms and Control for Infrastructure, V. Chaker, Ed., pp. 372-385, ASTM STP 1137, Philadelphia, PA, USA, 1992.

[5] O. Kayali and S. R. Yeomans, "Bond of ribbed galvanized reinforcing steel in concrete," Cement and Concrete Composites, vol. 22, no. 6, pp. 459-467, 2000.

[6] K. Hollinshead, Review of Literature on Silane Impregnations for Concrete in Highway Structures, Transport and Road Research Laboratory, Department of Transport, Berkshire, UK, 1989.

[7] P. C. Hewlett, "Methods of protecting concrete-coatings and linings," in Protection of Concrete, R. K. Dhir and J. W. Green, Eds., pp. 105-134, E and FN Spon, New York, NY, USA, 1990.

[8] P. A. M. Basheer, A. E. Long, and F. R. Montgomery, "Durability of surface treated concretem," Report no. SMRG-031992, Structural Materials Research Group, Department of Civil Engineering, The Queen's University of Belfast, Research Report to the Roads Service, Department of Environment (Northern Ireland), Belfast, Northern Ireland, 1992.

[9] ASTM D6237, Standard Guide for Painting Inspectors (Concrete Masonry Substrates), ASTM International, Pennsylvania, PA, USA, 2015.

[10] ASTM D4227, Standard Practice for Qualification of Coating Applicators for Application of Coatings to Concrete Surfaces, ASTM International, Pennsylvania, PA, USA, 2017.

[11] ASTM D6489, Standard Test Method for Determining the Water Absorption of Hardened Concrete Treated with a Water Repellent Coating, ASTM International, Pennsylvania, PA, USA, 2012.

[12] ASTM D5095, Standard Test Method for Determination of the Nonvolatile Content in Silanes, Siloxanes and Silane-Siloxane Blends Used in Masonry Water Repellent Treatments, ASTM International, Pennsylvania, PA, USA, 2013.

[13] ASTM D5860, Standard Test Method for Evaluation of the Effect of Water Repellent Treatments on Freeze-Thaw Resistance of Hydraulic Cement Mortar Specimens, ASTM International, Pennsylvania, PA, USA, 2013.

[14] K. Namoulniara, P.-Y. Mahieux, J. Lux, A. Aït-Mokhtar, and P. Turcry, "Efficiency of water repellent surface treatment: experiments on low performance concrete and numerical investigation with pore network model," Construction and Building Materials, vol. 227, p. 116638, 2019.

[15] A. R. Suleiman, A. M. Soliman, and M. L. Nehdi, "Effect of surface treatment on durability of concrete exposed to physical sulfate attack," Construction and Building Materials, vol. 73, pp. 674-681, 2014.

[16] B. Felekoğlu, "A method for improving the early strength of pumice concrete blocks by using alkyl alkoxy silane (AAS)," Construction and Building Materials, vol. 28, no. 1, pp. 305310, 2012.

[17] K. C. Vrancken, P. Van Der Voort, K. Possemiers, and E. F. Vansant, "Surface and structural properties of silica gel in the modification with $\gamma$-aminopropyltriethoxysilane," Journal of Colloid and Interface Science, vol. 174, no. 1, pp. 86-91, 1995.

[18] Z. Liu and W. Hansen, "Effect of hydrophobic surface treatment on freeze-thaw durability of concrete," Cement and Concrete Composites, vol. 69, pp. 49-60, 2016.

[19] J. Zhou, G. Ye, and K. van Breugel, "Characterization of pore structure in cement-based materials using 
pressurization-depressurization cycling mercury intrusion porosimetry (PDC-MIP)," Cement and Concrete Research, vol. 40, no. 7, pp. 1120-1128, 2010.

[20] S. Diamond, "Mercury porosimetry: an inappropriate method for the measurement of pore size distributions in cementbased materials," Cement and Concrete Research, vol. 30, no. 10, pp. 1517-1525, 2000.

[21] H. Ma, "Mercury intrusion porosimetry in concrete technology: tips in measurement, pore structure parameter acquisition and application," Journal of Porous Materials, vol. 21, no. 2, pp. 207-215, 2014.

[22] P. A. M. Basheer, L. Basheer, D. J. Cleland, and A. E. Long, "Surface treatments for concrete: assessmentmethods and reported performance," Construction and Building Materials, vol. 11, no. 7-8, pp. 413-429, 1997.

[23] D. Doran and B. Cather, Construction Materials Reference Book, Taylor \& Francis Routledge, Abingdon, UK, 2013.

[24] M. Levi, C. Ferro, D. Regazzoli, G. Dotelli, and A. Lo presti, "Comparative evaluation method of polymer surface treatments applied on high performance concrete," Journal of Materials Science, vol. 37, no. 22, pp. 4881-4888, 2002.

[25] H. Husni, M. R. Nazari, H. M. Yee et al., "Superhydrophobic rice husk ash coating on concrete," Construction and Building Materials, vol. 144, pp. 385-391, 2017.

[26] B. Sudbrink, M. Khanzadeh Moradllo, Q. Hu et al., "Imaging the presence of silane coatings in concrete with micro X-ray fluorescence," Cement and Concrete Research, vol. 92, pp. 121-127, 2017.

[27] K. Scrivener, "The use of backscattered electron microscopy and image analysis to study the porosity of cement paste," MRS Proceedings, vol. 137, p. 129, 1988.

[28] H. S. Wong, M. K. Head, and N. R. Buenfeld, "Pore segmentation of cement-based materials from backscattered electron images," Cement and Concrete Research, vol. 36, no. 6, pp. 1083-1090, 2006.

[29] D. A. Lange, H. M. Jennings, and S. P. Shah, "Image analysis techniques for characterization of pore structure of cementbased materials," Cement and Concrete Research, vol. 24, no. 5, pp. 841-853, 1994.

[30] A. A. Almusallam, F. M. Khan, S. U. Dulaijan, and O. S. B. AlAmoudi, "Effectiveness of surface coatings in improving concrete durability," Cement and Concrete Composites, vol. 25, no. 4-5, pp. 473-481, 2003.

[31] H. Y. Moon, D. G. Shin, and D. S. Choi, "Evaluation of the durability of mortar and concrete applied with inorganic coating material and surface treatment system," Construction and Building Materials, vol. 21, no. 2, pp. 362-369, 2007.

[32] L. Schueremans, D. Van Gemert, and S. Giessler, "Chloride penetration in RC-structures in marine environment - long term assessment of a preventive hydrophobic treatment," Construction and Building Materials, vol. 21, no. 6, pp. 1238-1249, 2007.

[33] J.-G. Dai, Y. Akira, F. H. Wittmann, H. Yokota, and P. Zhang, "Water repellent surface impregnation for extension of service life of reinforced concrete structures in marine environments: the role of cracks," Cement and Concrete Composites, vol. 32, no. 2, pp. 101-109, 2010.

[34] I. J. D. Vries and R. B. Polder, "Hydrophobic treatment of concrete," Construction and Building Materials, vol. 11, pp. 259-265, 1997.

[35] X. Pan, Z. Shi, C. Shi, T.-C. Ling, and N. Li, "A review on concrete surface treatment Part I: types and mechanisms," Construction and Building Materials, vol. 132, pp. 578-590, 2017.
[36] F. Pargar, M. Valipour, and M. Shekarchi, "Comparison of chloride diffusion in nine months concrete specimens containing metakaoline and silica fume pozzolans," in Proceedings of 6 th International Conference on Concrete under Severe Conditions, Environment and Loading (CONSEC 10), Yucatan, Mexico Taylor and Francis, London, UK, pp. 1013-1020, 2010.

[37] H. S. Wong, R. Barakat, A. Alhilali, M. Saleh, and C. R. Cheeseman, "Hydrophobic concrete using waste paper sludge ash," Cement and Concrete Research, vol. 70, pp. 9-20, 2015.

[38] M. H. F. Medeiros and P. Helene, "Surface treatment of reinforced concrete in marine environment: influence on chloride diffusion coefficient and capillary water absorption," Construction and Building Materials, vol. 23, no. 3, pp. 1476-1484, 2009.

[39] F. Tittarelli and G. Moriconi, "The effect of silane-based hydrophobic admixture on corrosion of galvanized reinforcing steel in concrete," Corrosion Science, vol. 52, no. 9, pp. 2958-2963, 2010.

[40] Y. Dong, N. Xie, A. Kessel, E. McVey, A. Pace, and X. Shi, "Accelerated laboratory evaluation of surface treatments for protecting concrete bridge decks from salt scaling," Construction and Building Materials, vol. 55, pp. 128-135, 2014.

[41] M. Ibrahim, A. S. Al-Gahtani, M. Maslehuddin, and F. H. Dakhil, "Use of surface treatment materials to improve concrete durability," Journal of Materials in Civil Engineering, vol. 11, no. 1, pp. 36-40, 1999. 